\title{
SISTEM MONITORING AGEN PADA XAVIER MARKS REALTY SURABAYA
}

\author{
Robertus Bagas ${ }^{1}$, Emmy Wahyuningtyas ${ }^{2}$ \\ Program Studi Teknik Informatika, Fakultas Teknik, Universitas Wijaya Kusuma Surabaya \\ ${ }^{1}$ robbagas@gmail.com, ${ }^{2}$ Emmy@if.uwks.ac.id
}

\begin{abstract}
Abstrak
Xavier Marks Realty merupakan perusahaan yang bergerak dibidang pemasaran properti. Berjalannya perusahaan, terdapat beberapa kendala yang menghambat pihak pimpinan untuk melakukan pengambilan keputusan. Tersedianya informasi yang dibutuhkan oleh pimpinan sangat lambat karena tiap agen masih harus menginputkan data closing penjualan secara manual melalui admin tidak secara langsung. Tujuan dari penelitian ini adalah untuk mewujudkan suatu sistem monitoring yang efektif, sekaligus untuk mempercepat tersedianya informasi untuk pimpinan. Hasil dari penelitian ini dapat berupa sistem monitoring agen yang mampu mengupdate data penjualan properti secara langsung melalui agen tanpa mengisi secara manual dan diinputkan melalui admin. Laporan pendapatan dari agen dan perusahaan akan langsung diterima oleh pimpinan sehingga memangkas kinerja admin. Sistem dapat menampilkan perkembangan penjualan agar tiap agen dapat meningkatkan kinerjanya dan pimpinan dapat memonitoring langsung agennya.
\end{abstract}

Kata Kunci : Sistem Monitoring, Pemasaran Properti, Closing Penjualan, Agen.

\begin{abstract}
Xavier Marks Realty is a company engaged in property marketing. The company runs, several obstacles prevent the leadership to make decisions. The availability of information needed by the leadership is very slow because each agent still has to enter sales closing data manually through the admin not directly. The purpose of this research is to create an effective monitoring system, as well as to accelerate the availability of information for leaders. The results of this study can be in the form of an agent monitoring system that can update property sales data directly through an agent without filling in manually and inputted through the admin. Earnings reports from agents and companies will be directly received by the leadership, thus cutting down the admin's performance. The system can display sales developments so that each agent can improve its performance and the leader can monitor directly the agent.
\end{abstract}

Keywords: Monitoring System, Property Marketing, Closing Sales, Agents.

\section{PENDAHULUAN}

Perkembangan teknologi setiap harinya berkembang semakin pesat. Salah satu teknologi yang telah banyak digunakan sekarang khususnya dalam suatu perusahaan adalah penerapan sistem monitoring yang dapat dilakukan secara efektif oleh aplikasi berbasis komputer yang dapat diakses dari mana saja pengguna berada. Umumnya monitoring sebagai suatu proses mengukur, mencatat, mengumpulkan, memproses dan mengkomunikasikan informasi untuk membantu pengambilan keputusan pimpinan pada suatu perusahaan. (Calyton dan Petry, 1983)

Xavier Marks Realty adalah salah satu perusahaan yang bergerak dibidang penjualan dan sewa properti. Perusahaan ini memiliki yang bertugas menjembatani investor atau pembeli dan penjual. Keberadaan agen properti sangat membantu pagi para penjual atau pembeli yang ingin membeli, menyewa, dan menjual properti yang diinginkan.
Para agen Xavier Marks Realty masih menggunakan sistem berbasis komputer yang belum mampu mengakomodasi dan membantu para agen yang jumlahnya cukup banyak. Setiap agen diharuskan untuk melakukan update perkembangan demi proses pemasaran properti meliputi area properti paling banyak terjual, jumlah properti yang terjual, jenis properti yang terjual, pendapatan tiap agen. Saat ini proses tersebut masih harus diinput secara manual oleh admin perusahaan. Agen tidak dapat update secara langsung, data perusahaan tidak update dengan cepat, sehingga pimpinan tidak bisa mendapatkan data dan informasi ketika sewaktu - waktu dibutuhkan untuk pendukung pengambilan keputusan kedepan untuk tiap agen yang tidak sesuai dengan target yang ditetapkan oleh perusahaan.

Untuk mewujudkan suatu sistem monitoring yang lebih cepat sesuai yang direncanakan oleh pimpinan, maka peneliti mengusulkan sistem monitoring yang mampu mengelola data agen agar 


\section{Melek IT}

Information Technology Journal. Vol 6 No 1 Januari 2020, 2 - 8

terupdate langsung dan mengupdate data perusahaan secara cepat. Sehingga sistem diharapkan dapat membantu .

\section{METODE}

Metode penelitian ini terdiri atas 3 tahap utama yaitu :

\subsection{Monitoring}

Siagian [1], Pengawasan sebagai proses pengamatan dari pada pelaksanaan seluruh kegiatan organisasi untuk menjalin agar semua pekerjaan yang sedang dilaksanakan berjalan sesuai dengan rencana yang telah di tentukan sebelumnya. Cassely dan Kumar [2], monitoring merupakan program yang terintegrasi, bagian penting dipraktek pimpinan yang baik dan arena itu merupakan bagian integral di pimpinan sehari-hari.

\subsection{Xavier Marks Realty}

Xavier Marks Realty menyediakan produk dan layanan terbaik untuk membantu properti konsumen terjual lebih cepat, serta memberikan kemudahan dan perlindungan bagi para calon pembeli dalam memperoleh rumah idaman.

Proses bisnis dari Xavier Marks Realty meliputi area properti paling banyak terjual, jumlah properti yang terjual, jenis properti yang terjual, dan pendapatan tiap agen.

\subsection{Sistem Informasi}

T. Sutabri [3], ada empat operasi dasar dari sistem informasi yaitu mengumpulkan, mengolah, menyimpan dan menyebarkan informasi. Informasi mungkin dikumpulkan dari lingkungan dalam atau luar dan memungkinkan didistribusikan ke dalam atau keluar organisasi.

Sistem informasi juga diartikan sebagai sistem di dalam suatu organisasi yang mempertemukan kebutuhan pengolahan transaksi harian yang mendukung fungsi operasi organisasi yang bersifat manajerial dengan kegiatan strategi dari suatu organisasi untuk dapat menyediakan kepada pihak luar tertentu dengan laporan-laporan yang diperlukan.

\section{HASIL DAN PEMBAHASAN}

\subsection{Tahapan Penelitian}

Berikut adalah alur metode penelitian proses pembuatan Sistem Monitoring Agen Properti Pada Xavier Marks Realty. penulis melakukan pengamatan terhadap sistem informasi yang berjalan pada Xavier Marks. Dari sistem informasi tersebut, mendapatkan beberapa kendala atau masalah pada sistem yang dapat menghambat kinerja perusahaan. Oleh sebab itu pada tahap ini penulis menentukan beberapa rumusan masalah sesuai hasil dari pengamatan untuk dijadikan sebagai acuan dan tujuan penelitian.

Dalam menjawab rumusan masalah dan pertanyaanpertanyaan penelitian, hasil penelitian harus disimpulkan secara eksplisit. Penafsiran terhadap temuan dilakukan dengan menggunakan logika dan teori-teori yang ada. Temuan berupa kenyataan di lapangan diintegrasikan/ dikaitkan dengan hasilhasil penelitian sebelumnya atau dengan teori yang sudah ada. Untuk keperluan ini harus ada rujukan. Dalam memunculkan teori-teori baru, teori-teori lama bisa dikonfirmasi atau ditolak, sebagian mungkin perlu memodifikasi teori dari teori lama.

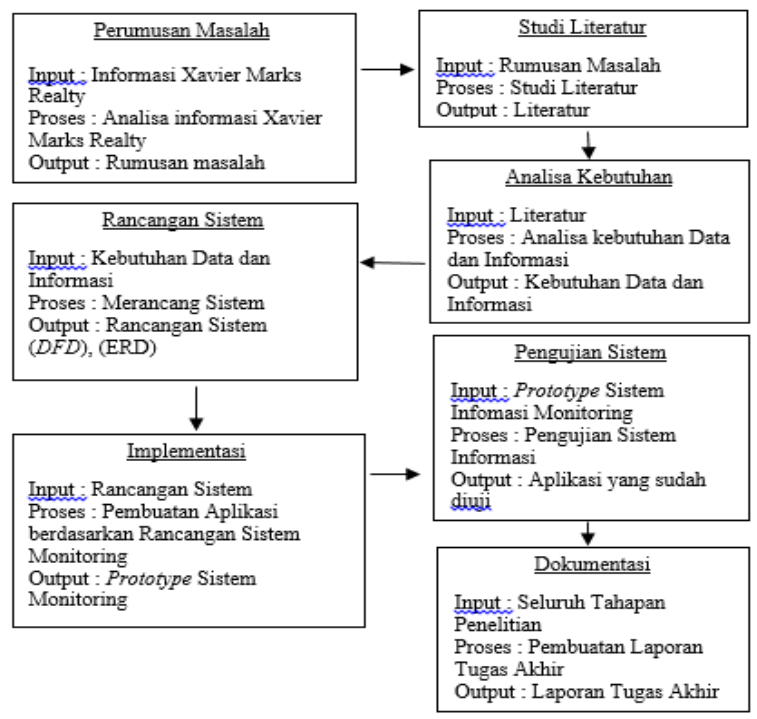

Gambar 1. Diagram Alur Penelitian

\subsection{Rancangan Sistem}

Pada tahap ini, penulis akan membuat rancangan sistem monitoring agen yang berupa diagram aliran data dan hubungan antar entitas berdasarkan analisa kebutuhan. Tools yang digunakan untuk merancang sistem monitoring agen ini menggunakan Power Designer 16. Hasilnya adalah berupa gambaran umum rancangan diagram aliran data dan hubungan antar entitas. Berikut adalah gambaran umum rancangan DFD

\subsubsection{DFD level context.}

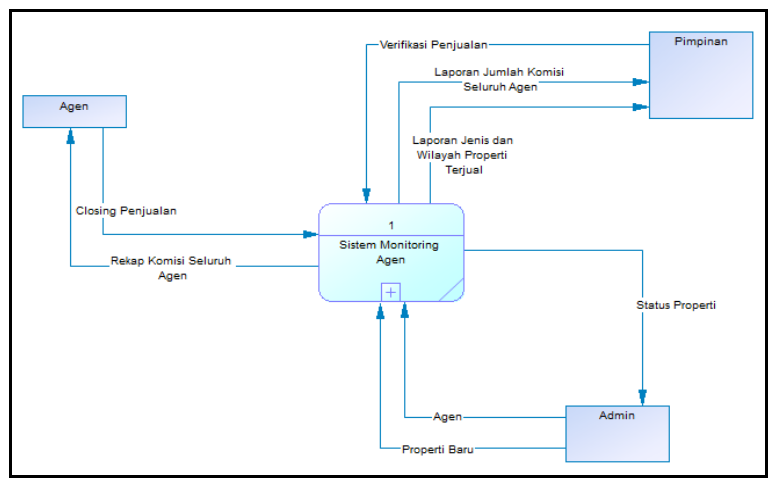

Gambar 2. DFD Level Context 


\section{pISSN: 2442-3386 elSSN: 2442-4293}

\subsubsection{DFD Level 1}

Setelah gambaran rancangan umum DFD level context telah dibuat. Maka dijabarkan kembali menjadi DFD level 1 yang terdapat 3 proses pada sistem yaitu kelola agen, kelola properti, dan closing penjualan properti. Dari 3 proses tersebut hasilnya akan disimpan dengan database agen, properti, dan closing properti.

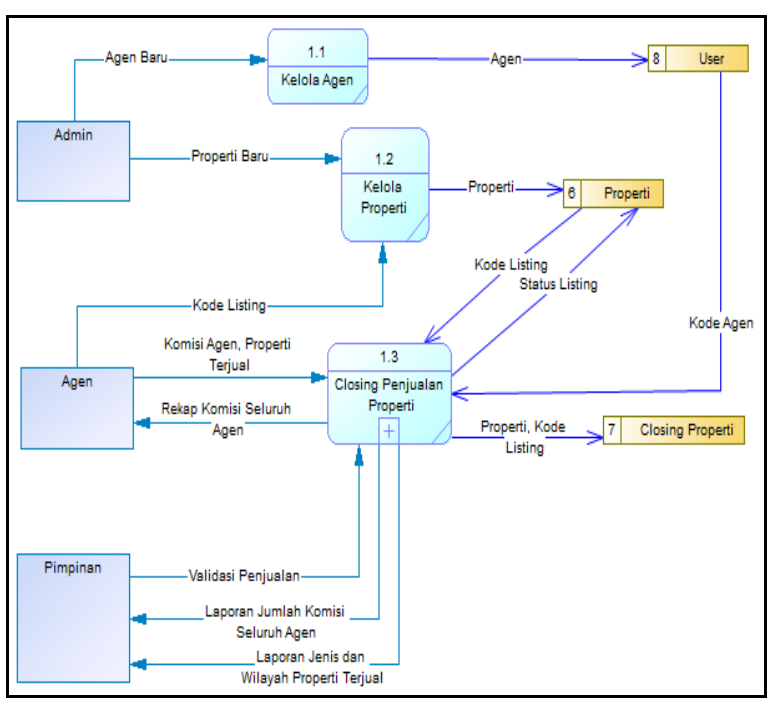

Gambar 3. DFD Level 1

\subsubsection{DFD Level 2}

Pada proses closing penjualan masih terdapat proses lagi yang dibutuhkan diantaranya validasi dan laporan penjualan. Proses closing penjualan akan dilakukan perhitungan pendapatan agen dan perusahaan dimana didapat dari 3\% harga penjualan. Kemudian dibagi 2 menjadi 1,5\% untuk agen dan $1,5 \%$ untuk perusahaan.

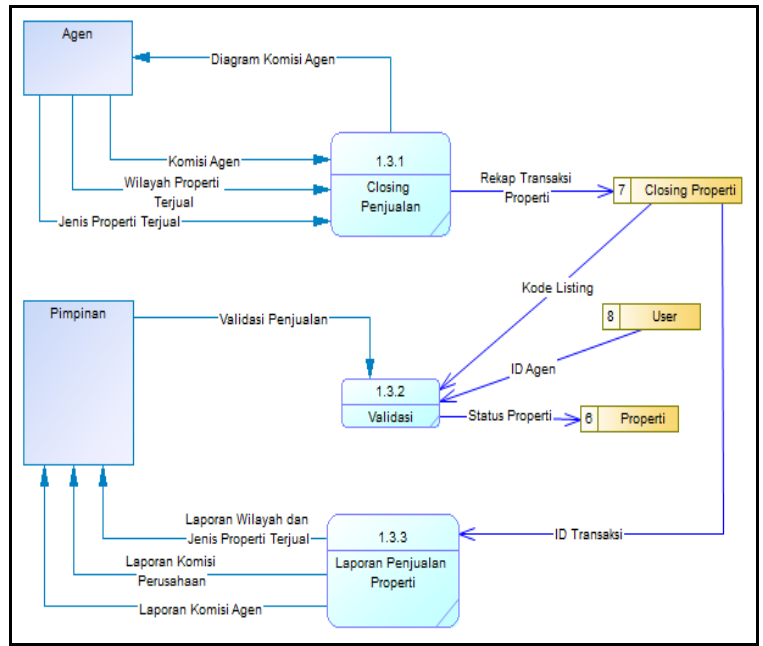

Gambar 4. DFD Level 2
Dalam rancangan sistem terdapat proses bisnis sistem monitoring agen pada Xavier Marks Realty yang dijabarkan sebagai berikut:

\subsubsection{Flowchart Proses Bisnis Kelola Agen}

Pada flowchart proses bisnis kelola agen, admin harus login terlebih dahulu. Setelah login admin akan memasukkan data agen yang ingin didaftarkan dalam sistem. Apabila data yang dimasukkan masih belum sesuai, admin dapat mengupdate data agen. Setelah itu selesai akan muncul notifikasi untuk validasi daftar agen. Laporan data agen akan dimunculkan kepada pimpinan.

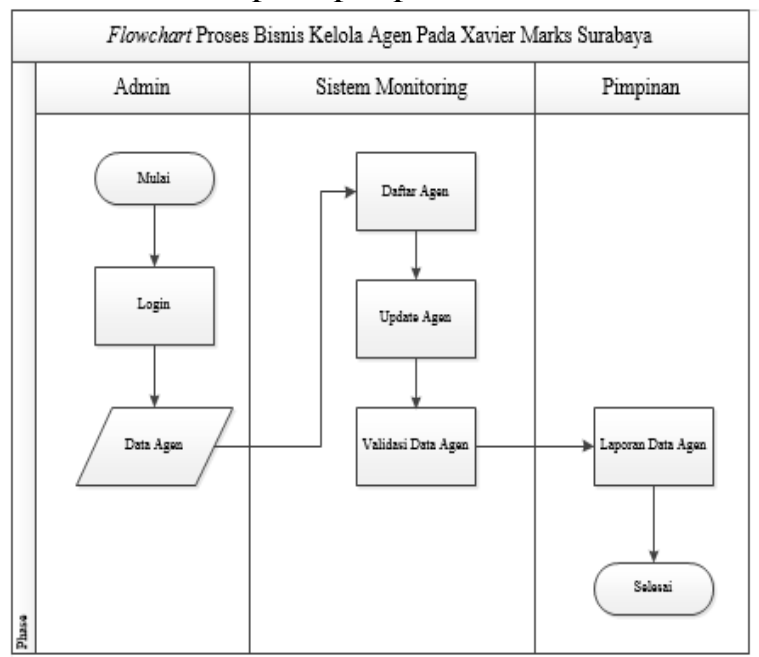

Gambar 5. Flowchart Proses Bisnis Kelola Agen

\subsubsection{Flowchart Proses Bisnis Kelola Properti}

Flowchart bisnis untuk kelola properti, yang mengelola adalah admin. Admin akan memasukkan data properti yang akan dijual ke dalam sistem. Setelah data telah dimasukkan, apabila properti tersebut sudah terjual maka agen harus memsukkan kode listing properti yang terjual kedalam. Sehingga disistem status properti tersebut akan terupdate. 


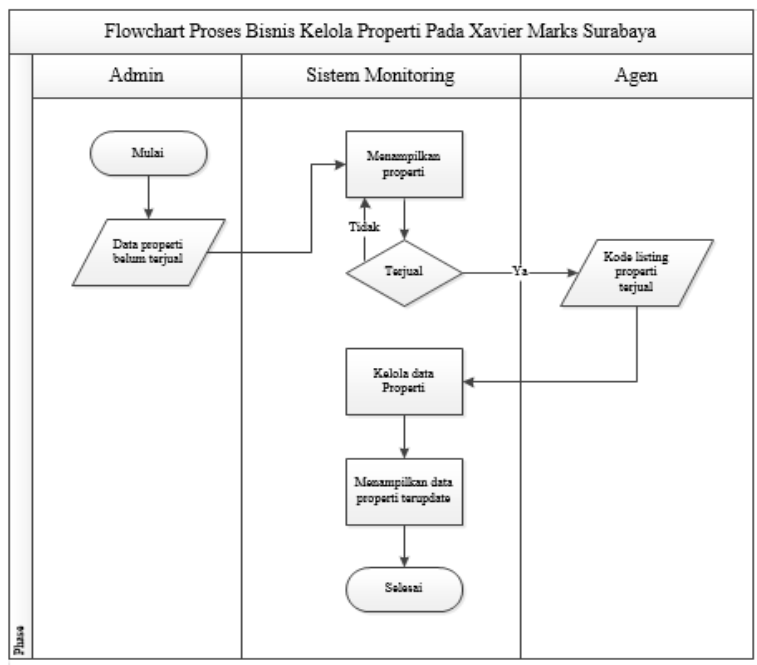

Gambar 6. Flowchart Proses Bisnis Kelola Properti

\subsubsection{Flowchart Proses Bisnis Closing Penjualan}

Flowchart bisnis untuk closing penjualan properti, diawali agen yang memasukkan data closing penjualan. Data tersebut meliputi data kode listing, harga, wilayah, dan jenis properti yang telah terjual. Kemudian pimpinan berperan untuk validasi penjualan data yang telah dimasukkan oleh agen. Pengurutan untuk jumlah komisi agen, wilayah dan jenis properti paling banyak terjual akan dilakukan oleh sistem. Data yang sudah diproses tersebut akan menjadi diagram yang ditujukan oleh agen. Dan laporan pendapatan dari agen dan perusahaan akan ditujukan ke pimpinan.

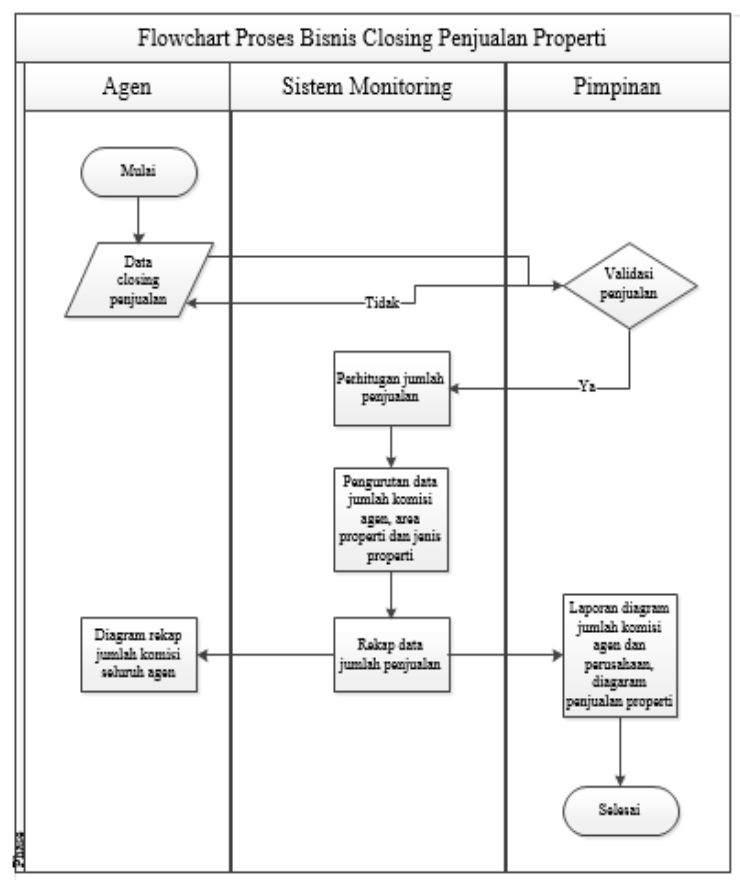

Gambar 7. Flowchart Proses Bisnis Closing Penjualan
Setelah DFD, terdapat rancangan basis data dari sistem yang diantaranya CDM dan PDM, yaitu sebagai berikut:

\subsubsection{CDM}

Merupakan gambaran yang lengkap dari struktur basis data yaitu entitas dan relasi atau hubungan antar relasi tersebut. Berdasarkan sistem monitoring yang dibuat dapat dianalisiskan seperti pada gambar 3.7. memiliki 6 tabel dan 6 relasi.

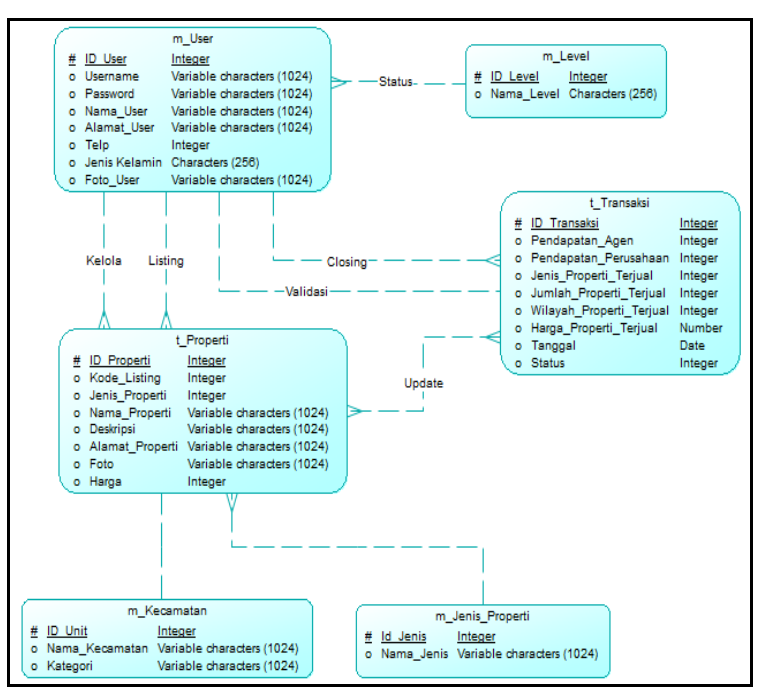

Gambar 8. CDM

\subsubsection{PDM}

Perancangan database secara fisik, tipe data bersifat lebih khusus dan spesifik. Perancangan PDM merupakan representasi fisik yang sebenarnya dari database. Setelah CDM dibuat dengan analisis yang sesuai sistem, maka akan dilakukan pengubahan menjadi PDM untuk menjadi rancangan fisik yang sesuai dengan tabel dan relasinya.

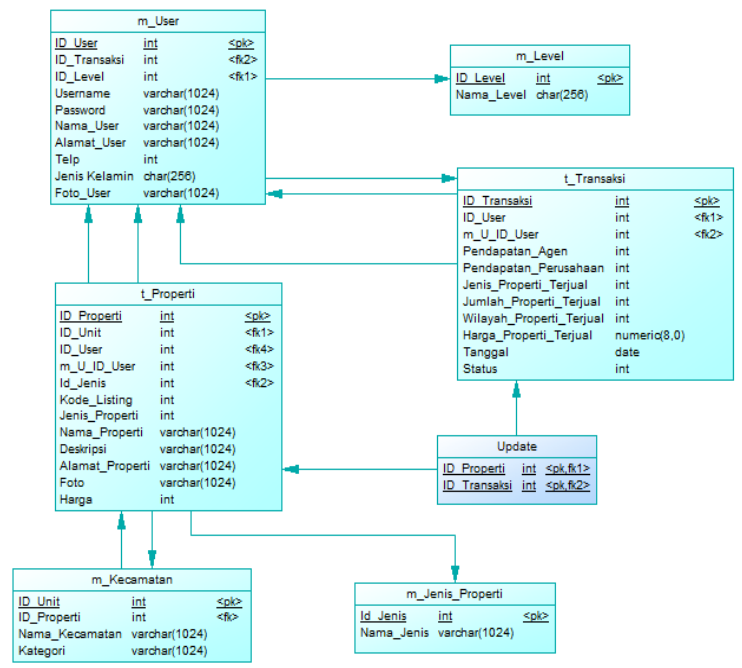




\section{pISSN: 2442-3386 elSSN: 2442-4293}

\section{Vol 6 No 1 Januari 2020, 5 - 8}

\section{Gambar 9. PDM}

\subsection{Halaman Login}

Setiap user yang ingin mengakses sistem harus melakukan login terlebih dahulu. User yang dimaksud adalah admin, agen, dan pimpinan.

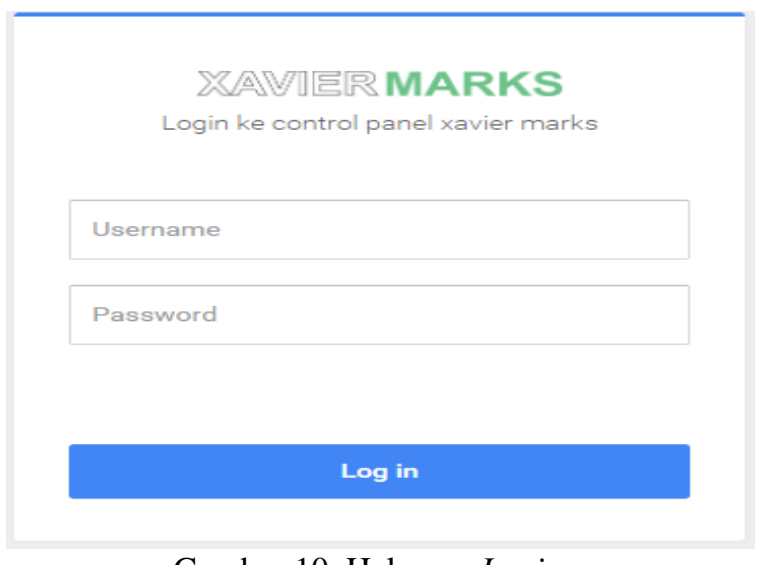

Gambar 10. Halaman Login

\subsection{Halaman Kelola Pegawai}

Pada halaman kelola pegawai terdapat daftar pegawai yang sudah ditambahkan oleh admin beserta biodatanya. Halaman ini digunakan admin untuk menambah pegawai baru maupun mengubah data dari pegawai.

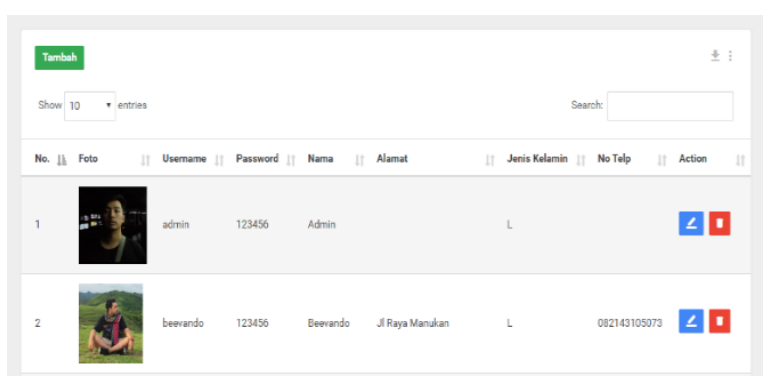

Gambar 11. Halaman Kelola Pegawai

\subsection{Halaman Tambah User}

Halaman ini digunakan admin untuk memasukkan data pegawai baru, agar pegawai tersebut dapat mengakses sistem.

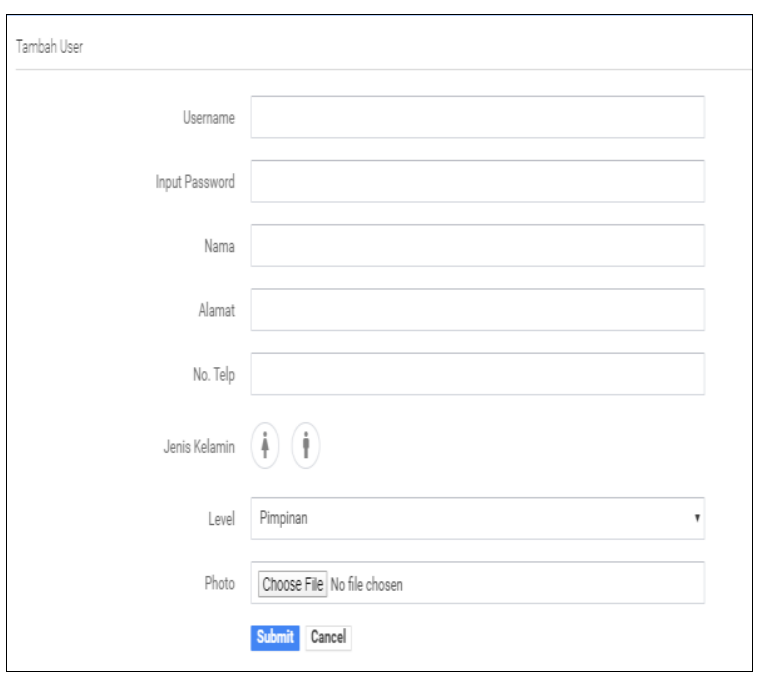

Gambar 12. Halaman Tambah User

\subsection{Halaman Kelola Properti}

Kelola properti digunakan sebagai halaman untuk mengubah data dari properti yang sebelumnya sudah dimasukkan oleh admin untuk dijual.

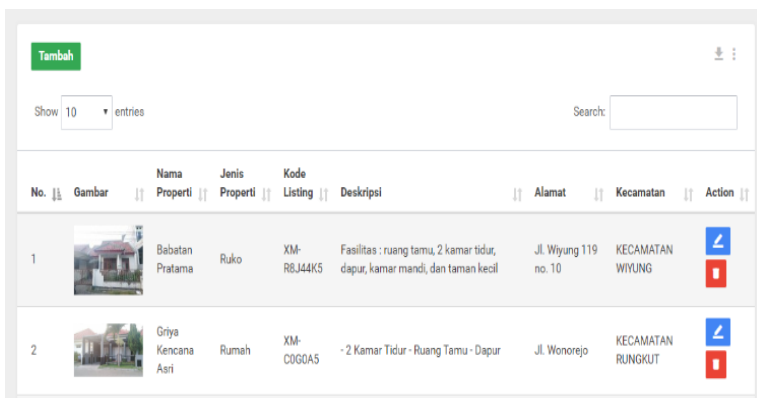

Gambar 113. Halaman Kelola Properti

\subsection{Halaman Tambah Properti}

Halaman tambah properti digunakan untuk memasukkan data properti yang akan dijual. Kode listing yang diinputkan sudah otomatis dimasukkan oleh sistem dan tidak dapat diubah. Data yang akan dimasukkan harus sesuai dengan agen yang menjual propertinya. 
Tambah Properti

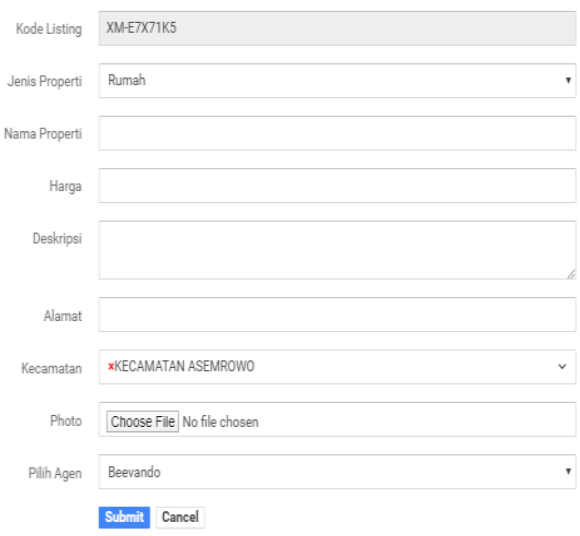

Gambar 14. Halaman Tambah Properti

\subsection{Halaman Entry Penjualan Agen}

Fitur entry penjualan terdapat pilihan kode listing sesuai dengan yang dijual oleh agen. Sehingga ketika kode listing dipilih, data alamat dan harga jual akan ditampilkan. Pada fitur harga penjualan, agen diharuskan memasukkan harga sesuai dengan kesepakatan.

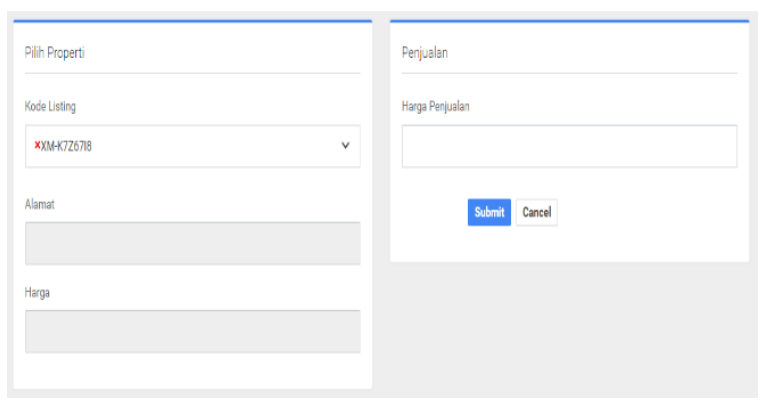

Gambar 15. Halaman Entry Penjualan Agen

\subsection{Halaman History Penjualan Agen}

Halaman ini menampilkan data penjualan yang sudah divaliadasi oleh pimpinan dengan tampilan warna hijau. Dan juga menampilkan data penjualan yang belum divalidasi oleh pimpinan dengan tampilan warna merah. Apabila data penjualan belum divalidasi oleh pimpinan, perhitungan jumlah pendapatan agen tidak akan muncul.

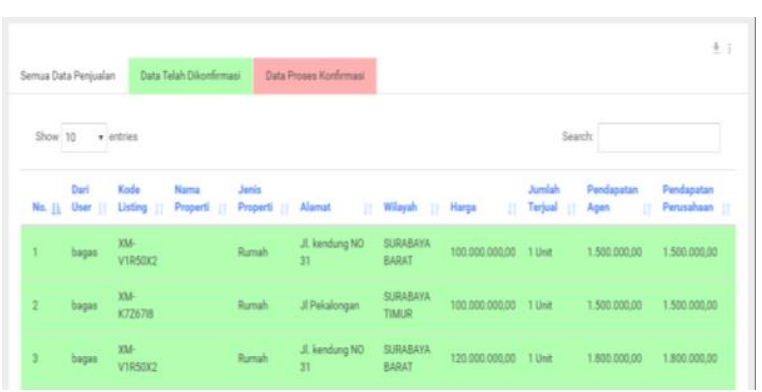

Gambar 16. Halaman History Penjualan Agen4

\subsection{Halaman Utama Pimpinan}

Sama dengan halaman utama admin dan agen, yang membedakan terdapat data penjualan masuk, history penjualan, dan laporan. Grafik yang ditampilkan adalah sebagai berikut:

1. Penjualan properti yang telah dilakukan tiap agen ditampilkan dengan grafik batang.

2. Total properti yang telah terjual ditampilkan dengan grafik lingkaran

3. Berdasarkan wilayah properti yang telah terjual ditampilkan dengan grafik lingkaran

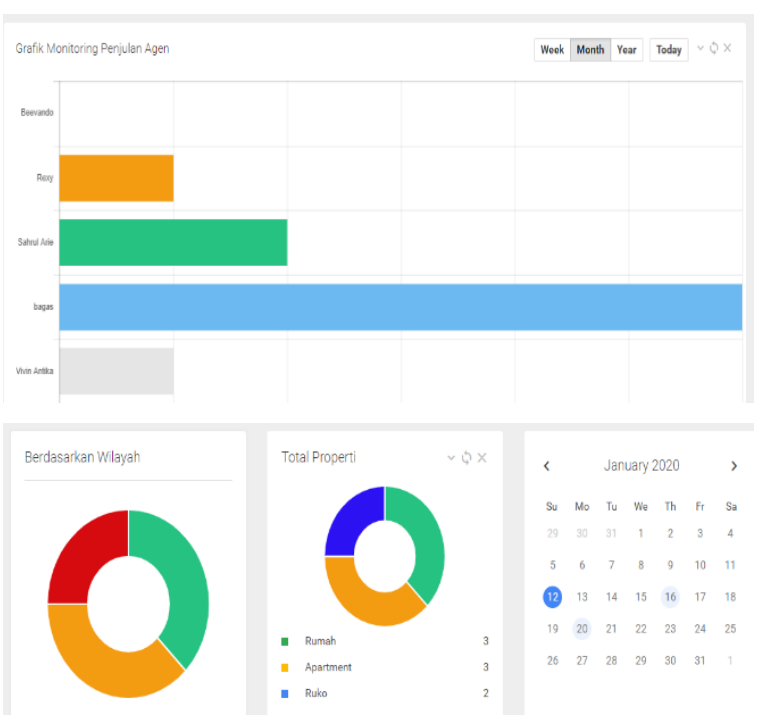

Gambar 17. Halaman Utama Pimpinan

\subsection{Halaman Validasi Data Penjualan Agen}

Halaman ini pimpinan melakukan validasi, agar proses perhitungan pendapatan agen dan perusahaan berjalan.

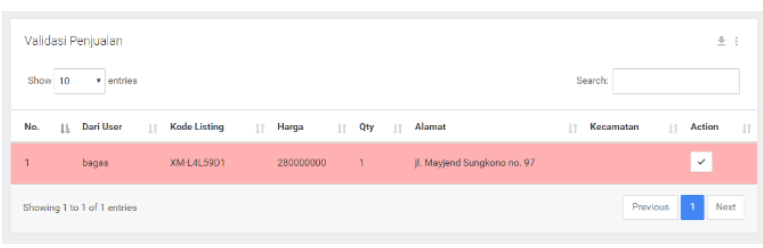

Gambar 18. Halaman Validasi Data Penjualan Agen

\subsection{Halaman Laporan Pendapatan}

Halaman ini memiliki fitur untuk menyaring laporan pendapatan sesuai dengan bulan dan tahun yang diinginkan oleh pimpinan.

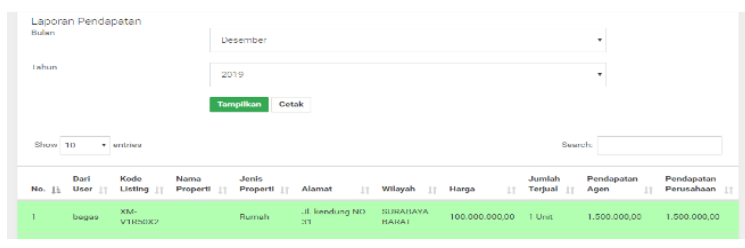

Gambar 19. Halaman Laporan Pendapatan 


\section{pISSN: 2442-3386 elSSN: 2442-4293}

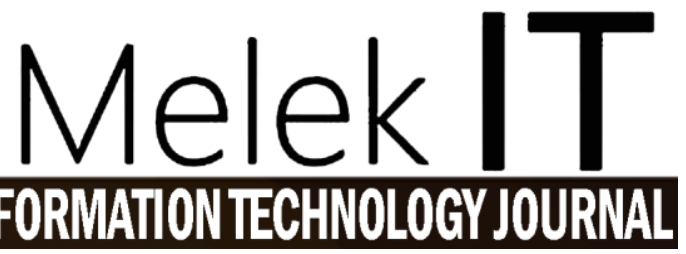

Pada gambar 17. merupakan hasil laporan pendapatan yang sudah diproses oleh sistem monitoring sehingga pimpinan mendapatkan laporan sesuai yang diinginkan.

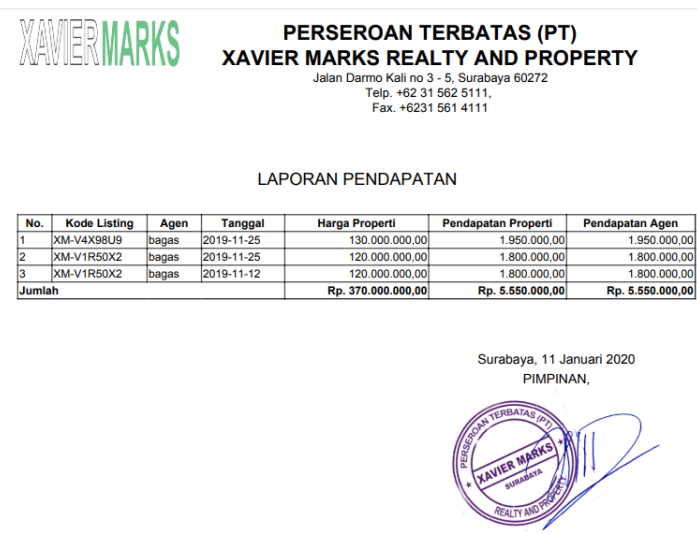

Gambar 20. Laporan Pendapatan

\section{PENUTUP}

\subsection{Kesimpulan}

Dari hasil dan analisa terhadap Sistem Monitoring Agen yang telah dibuat, didapat kesimpulan sebagai berikut :

1. Sistem mampu mengupdate data penjualan properti secara langsung melalui agen tanpa mengisi secara manual dan diinputkan melalui admin.

2. Laporan pendapatan dari agen dan perusahaan akan langsung diterima oleh pimpinan sehingga memangkas kinerja admin sehingga pekerjaan akan lebih ringan.

3. Sistem dapat menampilkan perkembangan penjualan sehingga tiap agen dapat meningkatkan kinerjanya dan pimpinan dapat memonitoring langsung agennya.

\subsection{Saran}

Saran dari hasil dan analisa terhadap Sistem Monitoring Agen yang telah dibuat adalah pengembangan Sistem Monitoring Agen Pada Xavier Marks realty agar dapat diakses melalui smartphone.

\section{DAFTAR PUSTAKA}

[1] gian, Sondang P. 1970. Filsafat Administrasi. Jakarta : Gunung Agung. 


\section{Melek IT}

Information Technology Journal. Vol 6 No 1 Januari 2020, 8 - 8

Halaman ini kosong

Redaksi MelekIT 